\title{
Fibroblast growth factor 2 regulation of mitral valve interstitial cell repair in vitro
}

Avrum I. Gotlieb, MD, CM

Alan Rosenthal, $\mathrm{PhD}$

Pedram Kazemian, BSc

From the Vascular Research Laboratory, Toronto General Hospital, University Health Network, Department of Laboratory Medicine and Pathobiology, University of Toronto, Toronto, Ontario, Canada.

Supported by Grant 3362 from the Heart and Stroke Foundation of Ontario.

Received for publication July 17, 2001; revisions requested Aug 28, 2001; revisions received Oct 17, 2001; accepted for publication Oct 24, 2001.

Address for reprints: Avrum I. Gotlieb, MD, Vascular Research Laboratory, Toronto General Hospital, UHN, 200 Elizabeth St, CCRW 1-857, Toronto, Ontario M5G 2C4 Canada (E-mail: avrum.gotlieb@ utoronto.ca).

J Thorac Cardiovasc Surg 2002;124:591-7

Copyright $\odot 2002$ by The American Association for Thoracic Surgery

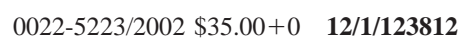

doi: $10.1067 / \mathrm{mtc} .2002 .123812$
Objective: Because elongated mitral valve interstitial cells have features of myofibroblasts, it is likely that these cells are essential for the repair of injured valve leaflets. We characterized the cellular morphology and pattern of repair of these interstitial cells in wounds produced in vitro and tested the hypothesis that fibroblast growth factor 2 enhances interstitial cell repair.

Methods: Mitral valve interstitial cells were plated onto glass coverslips, reached confluence after 1 week, and were wounded by passage of a spatula along the center of a monolayer, which created a linear wound with two edges. The wounds were observed from 0 to 96 hours by phase-contrast microscopy. Wounds were also fixed at 0,2 , and 24 hours and stained for fibroblast growth factor 2 and fibroblast growth factor receptor 1 by means of immunofluorescence and laser confocal microscopy.

Results: Cells in confluent monolayers and in the monolayer behind the wound edge formed a multilayered orthogonal pattern of elongated cells similar to fibroblasts. Cells along the wound edge migrated into the wound after 4 hours, and at 24 hours single cells with prominent lamellipodia and tails were present within the wound. There was overlapping of cells as well, similar to smooth muscle cells. Fibroblast growth factor 2 and fibroblast growth factor receptor 1 were present in the cells of the undisturbed confluent monolayer. They were upwardly regulated relative to the unwounded monolayer in the cells along the wound edge at 2 hours and in the monolayer behind the wound edge at 24 hours. In single cells that migrated into the wound, fibroblast growth factor 2 and fibroblast growth factor receptor 1 were prominent. Fibroblast growth factor 2 showed a 6 -fold increase in concentration relative to unwounded cultures in conditioned medium from wounded cultures at 2 hours after wounding. Addition of a neutralizing antibody to fibroblast growth factor 2 significantly delayed wound closure at 24 to 96 hours. Addition of exogenous fibroblast growth factor 2 to cultures at the time of wounding did not enhance wound repair.

Conclusion: Mitral valve interstitial cells have the ability to repair wounds, and fibroblast growth factor 2 is a modulator of these repair processes.

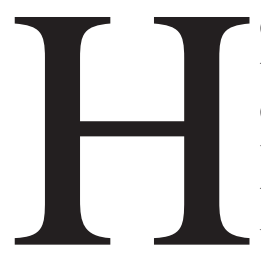

eart valves consist of complex layers of histologically distinct tissue that extend from the base of the valve toward the distal free edge. Although much is understood about the anatomy of cardiac valves, ${ }^{1-4}$ information about the cellular and molecular processes that regulate valve leaflet structure and function remain poorly understood.

Four types of cells are found in cardiac valve leaflets; valvular interstitial cells, endocardial endothelial cells, cardiac muscle cells, and smooth muscle cells. The surface of the leaflet is covered by endocardial endothelial cells, which extend as a continuous layer from the endocardial endothelial cells of the atria and ventricles. ${ }^{5}$ Cardiac muscle extends into the base of mitral and tricuspid valves. Valves may 
have some vascularity, especially toward the base, and smooth muscle cells are present in the walls of arterioles and venules. Short bundles of smooth muscle cells are also present. The most prevalent cell type in the valve is the cardiac valve interstitial cell. These cells are found in all layers of the valve and interact by means of gap and adherens junctions. In vivo, the valve interstitial cells have long cytoplasmic extensions, prominent adhesion and gap junctions, an incomplete basal lamina, and close association with extracellular matrix. ${ }^{6}$ Some interstitial cells show prominent microfilaments and intermediate filaments with less prominent rough endoplasmic reticulum and Golgi apparatus, whereas other cells show the opposite constellation. ${ }^{6}$ Interstitial cells appear to represent a heterogeneous population of cells with different phenotypic expressions. ${ }^{6-8}$ Some of the cells are thought to be of a myofibroblast type, ${ }^{9,10}$ whereas others may secrete the valve matrix, including collagen, elastin, and proteoglycans. ${ }^{6}$

Success in harvesting and culturing cardiac valve interstitial cells in monolayer cell culture ${ }^{6}$ and in organ culture ${ }^{11}$ has allowed new knowledge to be acquired about the structure and function of these cells. Cultured valve interstitial cells resemble fibroblasts morphologically, being elongated and forming an orthogonal pattern of overgrowth after confluence. ${ }^{6}$ The lack of a "hill and valley pattern" in postconfluent cultures distinguishes these cultures from those of vascular smooth muscle cells. ${ }^{12}$ Valvular interstitial cells show other differences from mesenchymal type cells. We have previously shown that there are differences between interstitial cells and endothelial and smooth muscle cells with respect to cell spreading and adhesion, two important processes related to cell migration and repair. ${ }^{7}$ In addition, Taylor and colleagues ${ }^{8}$ have shown that contractile functions of valve interstitial cells have differences from those of pericardial interstitial cells and skin fibroblasts.

The purpose of this study was to investigate the characteristics of in vitro mitral valve interstitial cell (MVIC) repair and the role of fibroblast growth factor 2 (FGF-2) in regulating this repair. The rationale was that FGF-2 has been shown to have a specific effect on the repair of vascular endothelial and smooth muscle cells. ${ }^{13,14}$ We carried out our experiments with an in vitro experimental wound made in a confluent monolayer as a model of interstitial cell repair.

\section{Material and Methods}

\section{Mitral Valve Interstitial Cell Cultures}

The anterior leaflet of the porcine mitral valve was used as a source of interstitial cells. ${ }^{6}$ Explants were derived from the distal portion of the valve, because occasional bundles of smooth muscle cells were present toward the base and very small blood vessels were most prominent toward the base. Briefly, the porcine heart was opened, and the distal third of the anterior leaflet of the mitral valve was rapidly removed and used for explant culture as previ- ously described elsewhere. ${ }^{6}$ To remove endocardial cells, the atrial and ventricular surfaces of the valve were scraped with a sterile scalpel blade and rinsed in sterile phosphate-buffered saline solution. Pieces that measured $4 \times 5 \mathrm{~mm}$ were cut from the tissue, placed in $35 \mathrm{~mm}$ tissue culture dishes (Falcon; BD Biosciences, San Jose, Calif), and grown in medium 199 (M-199), 10\% fetal bovine serum (FBS), and antibiotics in a humidified, 95\% air and $5 \%$ carbon dioxide atmosphere in an incubator at $37^{\circ} \mathrm{C}$. Cells began to grow out of the explant after 3 to 5 days. After 3 weeks, the cells that grew out of the explants were subcultured with $0.5 \mathrm{~g}$ of trypsin (1:250) and $0.2 \mathrm{~g} / \mathrm{L}$ of ethylenediaminetetraacetic acid in Hanks' buffered saline solution without calcium and magnesium ion (trypsin-edetic acid; GIBCO BRL; Life Technologies, Inc, Rockville, Md). The cells showed a growth pattern reminiscent of fibroblasts, as previously described elsewhere. ${ }^{6}$ In all experiments cell cultures of elongated cells were used from between 4 and 8 passages and grown in standard medium (M-199 and 5\% FBS).

\section{Wounding}

A series of serum concentrations from $0 \%$ to $10 \%$ were used to identify an optimum concentration, and 5\% FBS was used for most of the experiments. Three days after the cell cultures reached confluence, a single $1.5-\mathrm{mm}$ linear wound was made with a flatedged plastic cell scraper down the middle of the monolayer to create a double-sided wound. ${ }^{13}$ The time of wounding was designated as 0 hours. Cultures to be used in wound closure measurements were seeded in 6-well tissue culture plates. The plates were marked with small scratches made with a sterile diamond-tip pencil along the bottom exterior of each well and used as reference points to measure closure. Each wounded culture was rinsed three times with M-199 and then incubated with standard medium (M-199 plus 5\% FBS) with or without test agents. The extent of wound closure was measured at given time points and expressed as the extent of advancement of the cells into the wound at the reference scratches relative to the original wound edge at time 0 . Experiments were carried out at least three times with three dishes at each time point.

Wounded and unwounded cultures were photographed under phase-contrast microscopy with a photomicroscope (Nikon Diaphot; Nikon Canada, Mississauga, Ontario) through an $\times 10$ eyepiece and $\times 10$ objective. Photomicrographs were taken at 2, 6, 24, 48, and 96 hours with Kodak 2415 film (ASA 125; Kodak Canada, Toronto, Ontario) and developed with developer Kodak HC-110 (Kodak Canada) and printed on Kodabromide IIRC black and white F3 glossy paper (Kodak Canada).

\section{Localization of Fibroblast Growth Factor 2 and Fibroblast Growth Factor Receptor 1}

MVICs to be used in immunofluorescent studies were seeded on $22 \times 22$-mm sterile glass coverslips (Corning Incorporated, Corning, NY) in 35-mm tissue culture dishes (BD Bioscience, Oakville, Ontario, Canada). Unwounded confluent monolayers and wounded cultures were fixed and stained at various times after wounding to localize FGF-2 and fibroblast growth factor receptor 1 (FGFR-1). In addition, nuclei were localized with propidium iodide or SYTOX green staining (Molecular Probes, Inc, Eugene, Ore). Briefly, cells on the coverslips were fixed with ice-cold ethanol and acetic acid (95:5) for 4 minutes for FGF-2 localization or with 3\% 

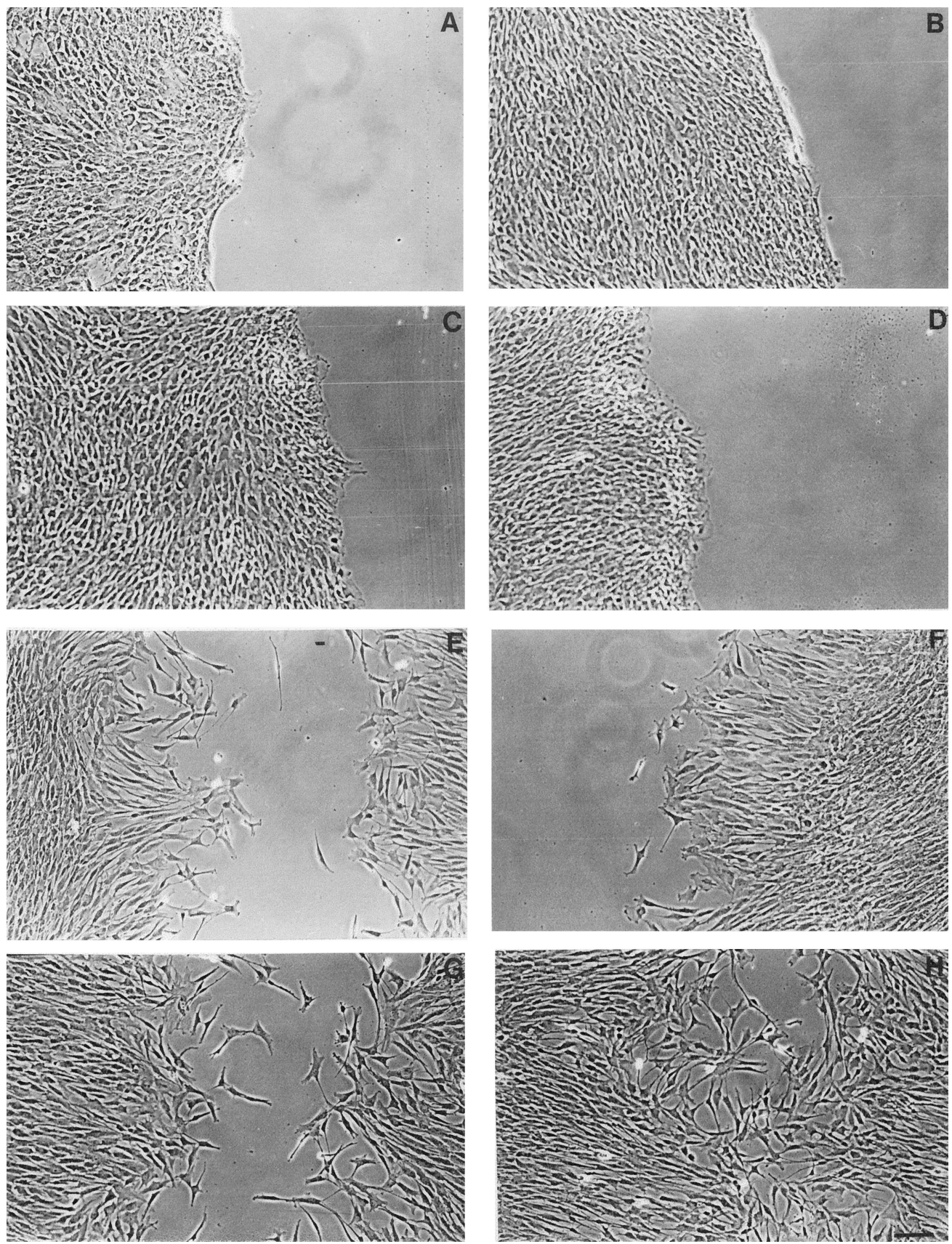

Figure 1. Phase-contrast photomicrographs of porcine MVICs grown in 5\% FBS (A, C, E, G) and $10 \%$ FBS (B, D, F, $H$ ) along wound edge show patterns of migration of elongated cells at 2 (A, B), 4 (C, D), 24 (E, F), and 48 (G, H) hours after wounding. All wounds were initially the same size. A, B, C, D, and F show cells along one edge; E, G, and H show cells along both wound edges. Note cells with frontal lamellipodia and tail (C, D). Note single cells and groups of cells present in wound early $(E, F)$, and note contacts being made between cell processes later $(G, H)$, as wounds closed. Wounds in $\mathbf{1 0} \%$ FBS closed more rapidly. Bar indicates $100 \mu \mathrm{m}$. Magnification $50 \times$.

paraformaldehyde for 10 minutes for FGFR-1 localization. This was followed by a 3.5-minute incubation with $0.1 \%$ Triton X-100 (The Dow Chemical Company, Midland, Mich) in phosphatebuffered saline solution to make the cells permeable. After three washes of 5 minutes each with phosphate-buffered saline solution, the coverslips were incubated for 1 hour at room temperature with a mouse monoclonal antibody against bovine brain basic FGF-2 (10 $\mu \mathrm{g} / \mathrm{mL}$; Upstate Biotechnology, Lake Placid, NY) or incubated overnight at $4^{\circ} \mathrm{C}$ with a rabbit antiserum against chicken FGFR-1 (1:100 dilution; Upstate Biotechnology). For negative control prepa- 


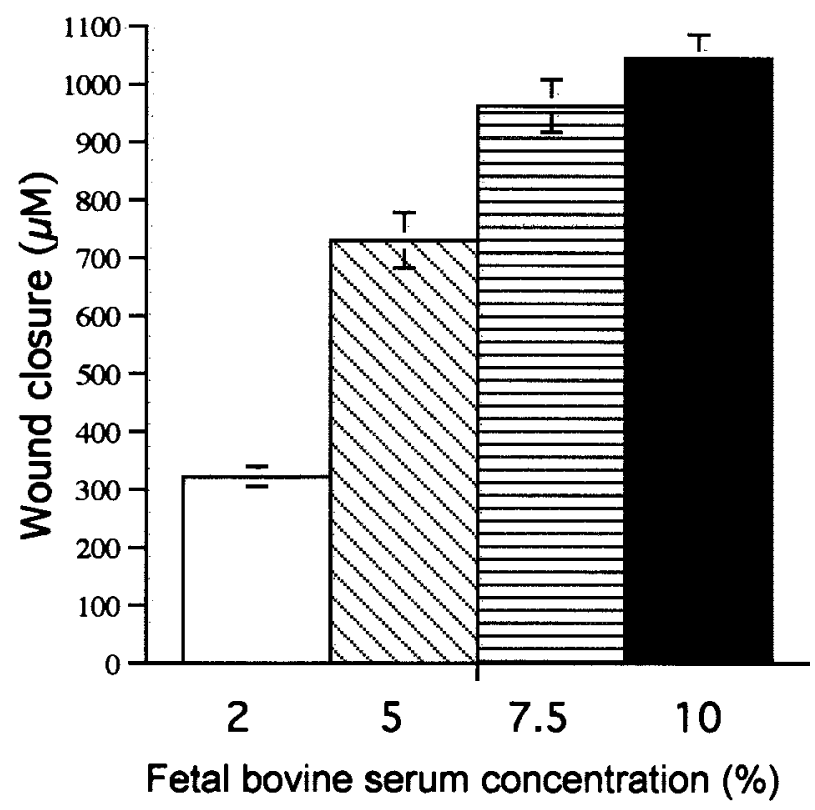

Figure 2. Wounded cultures of porcine MVICs showing extent of wound closure at $\mathbf{2 4}$ hours in cultures incubated with standard M-199 and varying concentrations of FBS. Error bars represent SD.

rations, nonimmune mouse immunoglobulin $\mathrm{G}$ and rabbit serum (Jackson Immuno Research, West Grove, Pa) were used. Secondary antibodies were goat antimouse Alexa 488 and goat antirabbit Alexa 568 immunoglobulin G (Molecular Probes). The coverslips were washed three times with phosphate-buffered saline solution between each of these steps. The stained coverslips were mounted with Fluoro Guard (Bio-Rad Laboratories Inc, Hercules, Calif).

The cells were examined with a scanning confocal laser imaging system (BioRad MRC 1024, BioRad, Toronto, Ontario, Canada) fitted with an argon-krypton mixed-gas laser with excitation wavelengths of 488, 568, and $647 \mathrm{~nm}$. The system was connected to a Nikon Optiphot microscope (Nikon Canada). Serial optical sections were taken at $0.5-\mu \mathrm{m}$ intervals, and projections of the optical sections were performed with the BioRad software. Color photographs were taken from the digital images with Photo Shop 5.0 software (Adobe Systems Incorporated, San Jose, Calif). All experiments were performed in triplicate.

\section{Enzyme-Linked Immunosorbent Assay}

FGF-2 concentration in culture medium at 2 hours after wounding was measured by enzyme-linked immunosorbent assay in wounded specimens and unwounded control specimens. We used a multiwound model in which the cells were seeded in a 100-mm tissue culture dish. Multiple wounds were made with a plastic comblike device, resulting in 24 linear wounds each $1.5 \mathrm{~mm}$ in width. Samples were assayed with the FGF-2 Quantikine immunoassay kit (R\&D Systems, Minneapolis, Minn) according to manufacturer instructions. Briefly, a blank, human recombinant FGF-2 standards ranging from 5 to $640 \mathrm{pg} / \mathrm{mL}$, and conditioned medium samples (all in duplicate) were added to individual wells of a 96-well plate previously coated with a monoclonal FGF-2 antibody. Samples were incubated for 2 hours, then incubated with a horseradish peroxidase-conjugated polyclonal FGF-2 antibody for 2 hours, and finally incubated with tetramethylbenzidine for 30 minutes, with intervening washes. The reaction was stopped with a premixed solution containing $2 \mathrm{~N}$ sulfuric acid and read spectrophotometrically on a Titertek Multiscan Plus plate reader (Titertek Instruments, Inc, Huntsville, Ala) at $450 \mathrm{~nm}$, with correction at $550 \mathrm{~nm}$. The concentration of FGF-2 was determined according to the graded curve generated from FGF-2 standards.

\section{Effects of Exogenous Fibroblast Growth Factor 2 and its Antibody}

Immediately after wounding, the cultures were rinsed with M-199 and incubated in standard medium (M-199 and 5\% FBS) with or without human recombinant FGF-2 (10 ng/mL; Upstate) or with or without $10-\mu \mathrm{g} / \mathrm{mL}$ neutralizing FGF-2 antibody (R \& D Systems, Minneapolis, MN). A control for neutralizing FGF-2 antibody was antiacidic FGF-1 (R\&D Systems) at $10 \mu \mathrm{g} / \mathrm{mL}$ in medium (M-199 and $5 \%$ FBS), which had no effect on wound repair.

\section{Statistical Analysis}

The Student $t$ test was performed to determine significant differences.

\section{Results}

\section{Interstitial Cells at Wound Edge}

The morphologic characteristics of the MVICs at the wound edge were observed at 2, 4, 24, and 48 hours after wounding (Figure 1). The elongated interstitial cells migrated outward from the wound edge 4 hours after wounding, with few contacts between cells. As the cells moved forward, many moved into the wound as single cells displaying a prominent frontal lamellipodia and a thin tail. Initially the frontal lamellipodia was directed at right angles to the wound edge in cells within the wound edge; however, once the cells were out into the wound edge, some had the frontal lamellipodia directed toward the monolayer or parallel to the wound edge. This suggests that once within the wound, MVICs were migrating independently of wound location or other cells in the wound. This surmise is supported by the finding that single cells did overlap each other well before the monolayer was reestablished as a confluent monolayer.

\section{Serum Effect on Wound Repair}

The extent of MVIC wound repair was dependent on serum concentration when measured at 24 hours after wounding (Figure 2).

\section{Localization of Fibroblast Growth Factor 2 and Fibroblast Growth Factor Receptor 1}

There was punctate immunolocalization of FGF-2 and FGFR-1 in undisturbed confluent monolayers and in the monolayer away 

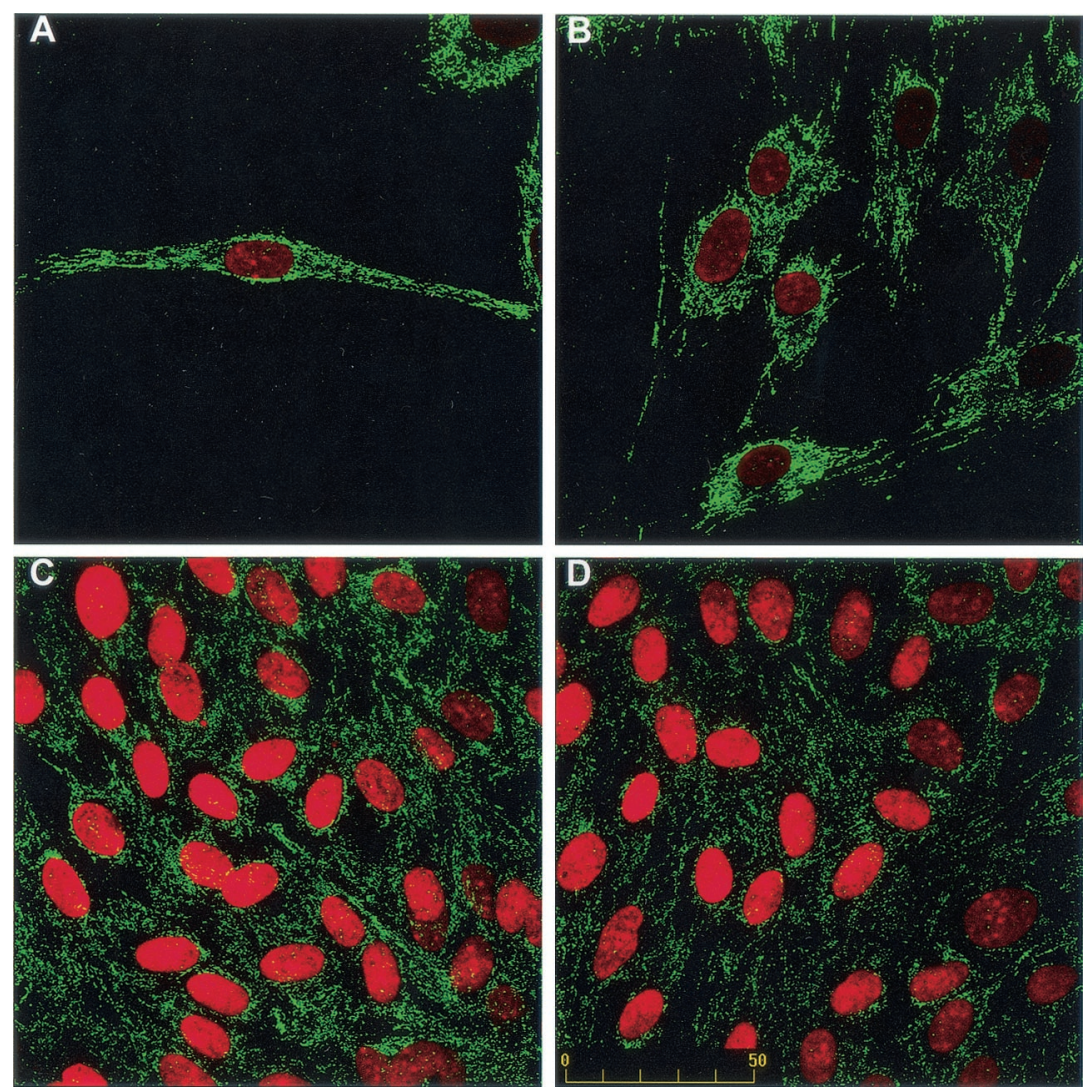

Figure 3. Immunofluorescent photomicrographs of interstitial cells 24 hours after wounding stained for FGF-2. Cell nuclei are stained with propidium iodide. A, Within wound; B, at wound edge; $C$, within monolayer in unwounded area; $D$, in unwounded monolayer. Bar indicates $50 \mu \mathrm{m}$. Magnification $600 \times$.

from the wound edge in wounded cultures (Figures 3 and 4). Both FGF-2 and FGFR-1 were distributed throughout the cell cytoplasm, with some nuclear staining. At 2, 24, 48, and 72 hours, cells at the wound edge and out in the wound showed enhanced staining for FGF-2 and FGFR-1, and FGFR-1 staining was prominent in the cell nucleus (Figures 3 and 4).

\section{Effect of Exogenous Fibroblast Growth Factor 2 and its Antibody}

Incubation of wounded cultures with FGF-2 neutralizing antibody was associated with decreases in repair at 48, 72, and 96 hours (Figure 5). Cultures incubated with antiFGF-1 did not show any difference in wound repair from untreated control cultures. Exogenous FGF-2 at $10 \mathrm{ng} / \mathrm{mL}$ did not show any enhanced repair (data not shown). The concentrations of FGF-2 in conditioned medium from cultures at 2 hours after wounding were $99 \pm 20 \mathrm{pg} / \mathrm{mL}$ in wounded cultures and $14 \pm 6 \mathrm{pg} / \mathrm{mL}$ in unwounded cultures $(P=.015)$.

\section{Discussion}

We are the first to report on the in vitro characteristics of MVICs. This in vitro model, a denuding wound made in a confluent monolayer, has been useful in characterizing endothelial, ${ }^{13}$ epithelial, ${ }^{15}$ and smooth muscle cell ${ }^{12}$ wound repair and in studying the regulation of repair. We found that the pattern of repair exhibited by MVICs was similar to that of smooth muscle cells ${ }^{12}$ and fibroblasts. The morphologic characteristics of the MVICs at the wound edge and in the wound were similar to those of smooth muscle cells and fibroblasts. ${ }^{12}$ The extent of MVIC repair was dependent on serum concentration and to some extent on the FGF-2 and its receptor, FGFR-1.

The MVICs repaired the wound in a fashion similar to that of smooth muscle cells ${ }^{12}$ and fibroblasts. ${ }^{16}$ The cells migrated free from the wound edge, and many cells migrated singly into the wound. Once out of the monolayer, the cells migrated in all directions, as indicated by the position of the frontal lamellipodia and the thin tail. Similar to smooth muscle cells, the MVIC overlapped each other well before confluence. We did not explore the role of matrix in regulating repair; however, this is likely to be important, because in vivo the interstitial cells are present in a 3-dimensional matrix within the valve leaflet. Likely matrix molecules that should be considered initially include 

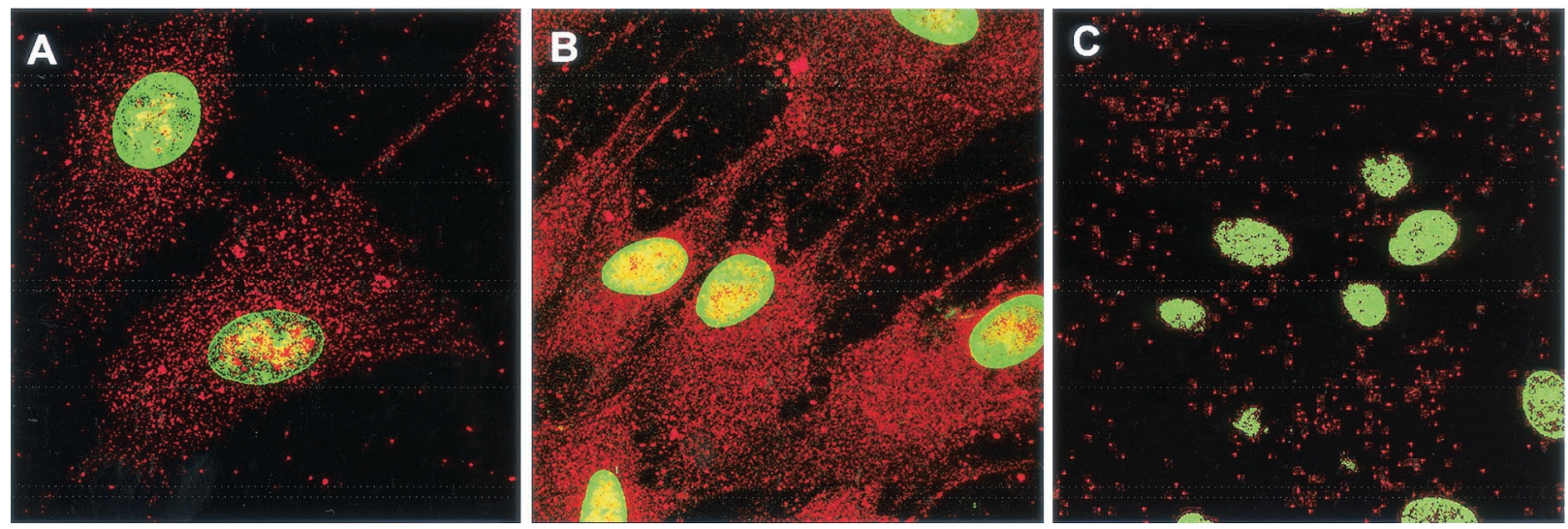

Figure 4. Immunofluorescent photomicrographs of interstitial cells stained for FGFR-1 at 24 hours after wounding. Cell nuclei are stained with SYTOX Green. A, Cells at wound edge; B, cells behind wound edge; C, cells within monolayer away from wound edge. Bar indicates $30 \mu \mathrm{m}$. Magnification $600 \times$.

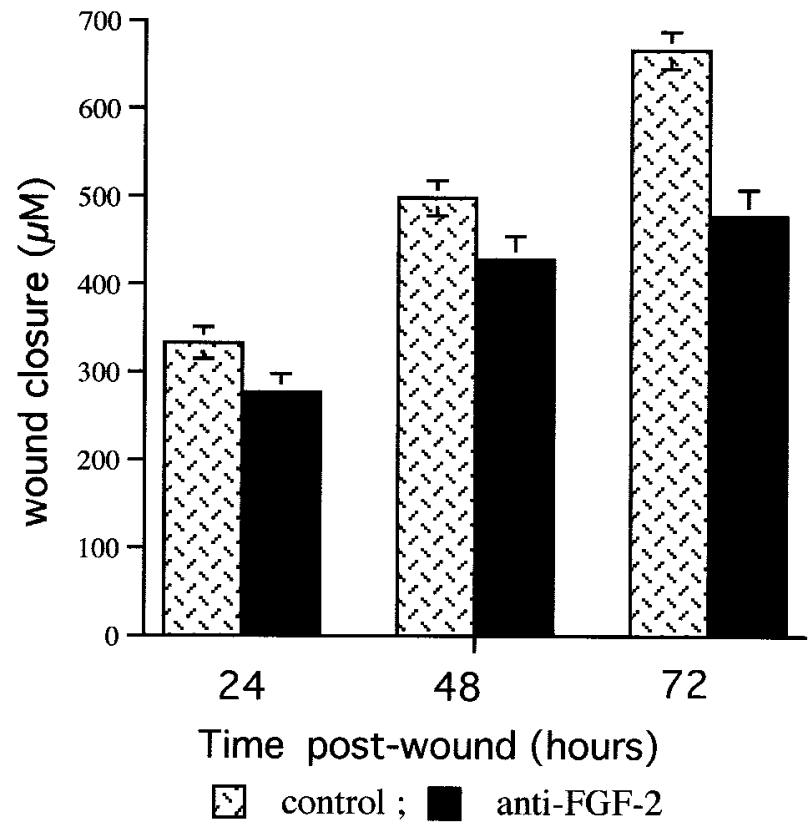

Figure 5. Experimental in vitro wounds of elongated MVICs incubated with (black bars) and without (hatched bars) antibody to FGF-2. Error bars represent SD. $P=.20, .045$, and .002 at 24,48 , and 72 hours.

collagens I, III, and VIII, ${ }^{17}$ osteopontin, ${ }^{18}$ and the metalloproteinases, ${ }^{19}$ a family of enzymes that degrade matrix and facilitate cell migration. In addition, the transformation of endocardial cardiac cushion cells to mesenchymal cells in the embryo is characterized by migration of the cells into and through the matrix of the cardiac cushion to become the future interstitial cells of the valve. ${ }^{20}$

We found that FGF-2, a member of a large family of polypeptides that play roles in cell growth and differentia- tion and in wound healing, ${ }^{21}$ and its receptor FGFR-1, ${ }^{22}$ a high-affinity transmembrane tyrosine kinase receptor, were upwardly regulated in MVICs within the wound, in cells at the wound edge, and in cells just behind the edge. Cells well away from the wound edge and in unwounded monolayers showed less staining. The conditioned medium of the wounded monolayer did show a 6-fold increase in FGF-2 after wounding, which explains in part why neutralizing antibodies to FGF-2 reduce the rate of wound closure. FGF-2 and FGFR-1 have been shown to enhance vascular cell migration and repair of both endothelial cells ${ }^{13}$ and smooth muscle cells. ${ }^{23}$ Our findings are thus important from a therapeutic viewpoint, because FGF-2 also appears to promote valve repair and thus any vascular therapies with FGF-2 would not adversely affect valve repair. The mechanisms of action of FGF-2 have not been identified, although we have shown that FGF-2 promotes both an actin cytoskeleton orientation that favors migration ${ }^{14}$ and an orientation of centrosomes and microtubules that enhances directed cell migration. ${ }^{13}$ We have not explored the mitogenic effect of FGF-2 on the proliferative component of MVIC wound repair. ${ }^{24}$ Because FGF-2 is known to be mitogenic, ${ }^{25}$ it is likely that there is a mitogenic effect in addition to the effect on cell migration. The finding that FGFR-1 is expressed in the nuclei of cells involved in repair is consistent with a recent report that FGFR-1 translocates to the nucleus and nuclear FGFR-1 induces C-Jun and is involved in the regulation of cell proliferation. ${ }^{26}$

Our previous studies ${ }^{11}$ and those of others ${ }^{27,28}$ have shown that MVICs repair wounds in valve organ culture systems. Recent studies have shown that interstitial cells repair sheep valves in vivo. ${ }^{29}$ In our current studies, we were able to use the simple in vitro experimental wound model system to begin to understand the regulation of repair. An understanding of the regulation of the interstitial cell repair 
processes will enhance our ability to optimize surgical procedures that require repair of valve leaflets, ${ }^{30,31}$ to design better prosthetic valves, ${ }^{32}$ and to develop strategies for successful cardiovascular tissue engineering. ${ }^{33}$

\section{References}

1. Silver MM, Freedom RM. Gross examination and structure of the heart. In: Silver M, editor. Cardiovascular pathology, 2nd ed. New York: Churchill Livingstone; 1991. p. 1-42.

2. Ranganathan N, Lam JH, Wigle ED, Silver, MD. Morphology of the human mitral valve II: the valve leaflets. Circulation. 1970;61:459-67.

3. Barlow JB, Antunes MJ. Functional anatomy of the mitral valve. In: Barlow JB, editor. Perspectives on the mitral valve. Philadelphia: F.A. Davis; 1987. p. 8-14.

4. Kunzelman KS, Cochran RP, Verrier ED, Eberhart RC. Anatomic basis for mitral valve modelling. J Heart Valve Dis. 1994;3:491-6.

5. Andres, LJ, Sys SU, Brutsaert DL. Morphoregulatory interactions of endocardial endothelium and extracellular material in the heart. Herz. 1995;20:135-45.

6. Lester W, Rosenthal A, Granton B, Gotlieb AI. Porcine mitral valve interstitial cells in culture. Lab Invest. 1988;59:710-9.

7. Zacks S, Rosenthal A, Granton B, Havenith M, Opas M, Gotlieb AI. Characterization of cobblestone mitral valve interstitial cells. Arch Pathol Lab Med. 1991;115:774-9.

8. Taylor PM, Allen SP, Yacoub MH. Phenotypic and functional characterization of interstitial cells from human heart valves, pericardium and skin. J Heart Valve Dis. 2000;9:150-8.

9. Filip DA, Radu A, Simionescu M. Interstitial cells of the heart valves possess characteristics similar to smooth muscle cells. Circ Res. 1986;59:310-20

10. Gabbiani G. The biology of the myofibroblast. Kidney Int. 1992;41: 530-2.

11. Lester WM, Gotlieb AI. In vitro repair of the wounded porcine mitral valve. Circ Res. 1988;62:833-45.

12. Gotlieb AI, Spector W. Migration into an in vitro experimental wound: a comparison of porcine aortic endothelial and smooth muscle cells. Am J Pathol. 1981;103:271-82

13. Ettenson DS, Gotlieb AI. Basic fibroblast growth factor is a signal for the initiation of centrosome redistribution to the front of migrating endothelial cells, at the edge of an in vitro wound. Arterioscler Thromb Vasc Biol. 1995;15:515-21.

14. Wang D, Gotlieb AI. Effect of FGF-2 on the early stages of in vitro endothelial repair. Exp Mol Pathol. 1999;66:179-90.

15. Gordon SR, Staley CA. Role of the cytoskeleton during injury-induced cell migration in corneal endothelium. Cell Motil Cytoskeleton. 1990;16:47-57.

16. Sheetz MP, Felsenfeld DP, Galbraith CG. Cell migration: regulation of force on extracellular matrix-integrin complexes. Trends Cell Biol. $1998 ; 8: 51-4$.
17. Hou G, Mulholland D, Gronska MA, Bendeck MP. Type VIII collagen stimulates smooth muscle cell migration and matrix metalloproteinase synthesis after arterial injury. Am J Pathol. 2000;156:467-76.

18. O'Brien KD, Kuusisto J, Reichenback DD, Ferguson M, Giachelli $\mathrm{CM}$, Alpers CE, et al. Osteopontin is expressed in human aortic valvular lesions. Circulation. 1995;92:2163-8.

19. Edep ME, Shirani J, Wolf P, Brown DL. Matrix metalloproteinase expression in nonrheumatic aortic stenosis. Cardiovasc Pathol. 2000; 9:281-6.

20. Bernanke DN, Markwald RR. Migratory behavior of cardiac cushion tissue cells in a collagen lattice system. Dev Biol. 1982;91:235-45.

21. Kanda S, Hodgkin MN, Woodfeild RJ, Wakelam MJ, Thomas G, Claesson-Welsh L. Phosphatidylinositol 3'-kinase-independent p70 S6 kinase activation by fibroblast growth factor receptor-1 is important for proliferation but not differentiation of endothelial cells. J Biol Chem. 1997:272:23347-53.

22. Johnson DE, Williams LT. Structural and functional diversity in the FGF receptor multigene family. Adv Cancer Res. 1993;60:1-41.

23. Daley SJ, Gotlieb AI. Fibroblast growth factor receptor 1 expression is associated with neointimal formation in vitro. Am J Pathol. 1996; 148:1193-202.

24. Bailly K, Soulet F, Leroy D, Amalric F, Bouche G. Uncoupling of cell proliferation and differentiation activities of basic fibroblast growth factor. FASEB J. 2000;14:333-44.

25. Pages G, Lenormand P, L'Allemain G, Chambard JC, Meloche S, Pouyssegur J. Mitogen-activated protein kinases P42mapk and P44mapk are required for fibroblast proliferation. Proc Natl Acad Sci U S A. 1993;90:8319-23.

26. Reilly JF, Maher PA. Importin beta-mediated nuclear import of fibroblast growth factor receptor; role in cell proliferation. J Cell Biol. 2001;152:1307-12.

27. Lester WM, Damji AA, Tanaka M, Gedeon I. Bovine mitral valve organ culture: role of interstitial cells in repair of valvular injury. $J$ Mol Cell Cardiol. 1992;24:43-53.

28. Lester WM, Damji AA, Gedeon I, Tanaka M. Interstitial cells from the atrial and ventricular sides of the bovine mitral valve respond differently to denuding endocardial injury. In Vitro Cell Dev Biol. 1993; 29A:41-50.

29. Tamura K, Jones M, Yamada I, Ferrans VJ. Wound healing in the mitral valve. J Heart Valve Dis. 2000;9:53-63.

30. Lau KW, Ding ZP, Hung JS. Percutaneous transvenous mitral commissurotomy versus surgical commissurotomy in the treatment of mitral stenosis. Clin Cardiol. 1997;20:99-106.

31. Grossi EA, Galloway AC, Miller JS, Ribakove GH, Culliford AT, Esposito R, et al. Valve repair versus replacement for mitral insufficiency: when is a mechanical valve still indicated? J Thorac Cardiovasc Surg. 1998;115:389-94.

32. Schoen FJ. Valvular heart disease in interventional and surgical cardiovascular pathology. In Schoen FJ, editor. Philadelphia: WB Saunders; 1989. p. 109-71.

33. Durbin A, Gotlieb AI. Advances towards understanding heart valve response to injury. Cardiovasc Pathol. 2002;11:69-77. 